\title{
SELF-REFLECTION OF STUDENTS OF ECONOMIC TEACHING AND THEIR PERSONAL CONSTRUCT OF EXPERT-TEACHER
}

\author{
Kristýna Krejčová ${ }^{1 \bowtie}$
}

${ }^{1 凶}$ Department of Economic Teaching Methodology, Faculty of Finance and Accounting, University of Economics, Prague, Czech Republic, nám. W. Churchilla 4, Prague 3,130 67, +420 224095 134, kris.krejcova@gmail.com

\author{
Highlights \\ - $\quad$ Students referred more about their strengths than about their weaknesses \\ - $\quad$ Personality, Social skills and Will were the most frequent categories \\ - Future teachers' construct of a good teacher affects their self-reflection as a teacher \\ - Self-reflective essay is useful method for development of auto-diagnostic skills
}

\section{Abstract}

To be efficient and satisfied in his/her profession, a teacher needs to realize adequately his/her strengths and weaknesses. To support development of self-reflective skills by future teachers, students at Department of Economic Teaching Methodology at University of Economics in Prague were asked to write an essay called 'Why am I supposed to be a good teacher?'

Content analysis of self-reflective statements and participants' personal construct of expert teacher bring important feedback information about skills that should be trained during the education of prospective teachers. Participants consider the self-reflective essay as enriching method that helped them to realize their strengths and weaknesses and to develop their self-reflective skills as an important part of professional expertise.

\section{Keywords}

Personal construct, personality of prospective teacher, self-reflection, social skills, teachers' education

Krejčová K. (2016) "Self-Reflection of Students of economic teaching and Their Personal Construct of Expert-Teacher", Journal on Efficiency and Responsibility in Education and Science, Vol. 9, No. 1, pp. 17-22, online ISSN 1803-1617, printed ISSN 23362375, doi: 10.7160/eriesj.2016.090103.

\section{Introduction}

In a context of escalating requirements on a teacher's personality, many attempts to classify professional skills of a teacher appeared (Sternberg, Horvath, 1995; Kyriacou, 1998; Gillernová, 2008). Kyriacou (1998) created categorization of teacher's essential skills consisting of seven areas: planning and preparation, lesson presentation, lesson management, establishing a positive classroom climate, discipline, assessing pupils' progress, reflection and evaluation). Sternberg and Horvath (1995) described an 'expert-teacher' by declaring a prototype that consists of three characteristics: knowledge base, efficiency (involving executive control) and insight. Gillernová (2008) defined four areas of professional skills of a teacher: theoretical skills (connected with the subject he/she is teaching), didactic skills, diagnostic skills and social skills. Despite their differences, all these models of professional skills of a teacher have some common features. One of them is the emphasis on auto-diagnostic skills and self-reflection.

The self-reflection or auto-diagnostic skills could be defined as the teachers' ability to understand their personalities, recognize their weaknesses as well as strengths that help them to develop high level of self-awareness (Zeren, 2012). Moreover, 'teachers with a high degree of self-awareness are expected to be more understanding towards their students because understanding others requires one to understand herself first' (Zeren, 2012: 2445). Švarcová (2010) defined the self-reflection ability as a crucial part of social intelligence: 'The social intelligence might be divided into two types: interpersonal intelligence, which means the ability to act with others, to perceive the needs of others, to emphasize easily with others, and intrapersonal intelligence, which refers to the self-reflective capacities, understanding of the self and own behavior and the skill to take control of it' (Švarcová, 2010: 41). The ability of self-reflection is strongly connected with self-perception (Hayes, 1993) and with the level of self-efficacy (Bandura, 1977: 194): 'Efficacy expectations determine how much effort people will expend and how long they will persist in the face of obstacles and aversive experiences. The stronger the perceived self-efficacy, the more active the efforts.'

There is a growing tendency to teach teachers how they should help their students to reflect themselves (e.g. Freddano, Siri, 2012; Körpülü, 2012). 'Culture of evaluation among schools and self-evaluation within schools are gradually developing with the scholastic autonomy system' (Freddano, Siri, 2012: 1142). Apart from that, many studies focus on enrichment of teachers' abilities to observe and regulate their own teaching styles, communication styles and other forms of behavior. Some of the studies deal with prospective teachers, incorporating the self-reflection into their pre-gradual preparation (Mogonea, Mogonea, 2013; Majzub, 2013; Zeren, 2012).

Mogonea and Mogonea (2013) used the psycho-pedagogical experiment with prospective teachers using self-correction or mutual correction, controlled self-grading, mutual grading, objective inter-assessment method (Mogonea, Mogonea, 2013: 533). They found out that frequent use of self-evaluative method and the usage of metacognitive skills lead to significant progress in self-assessment abilities in the experimental group. Authors confirmed their hypothesis that developing of metacognitive skills has positive effect on the process of self-reflection.

Majzub (2013) used qualitative analysis of narratives that students wrote during their teaching practicum at schools. 
Author concluded that the self-reflective reports during teaching practicum had positive impact on future teacher's awareness of their learning and teaching skills and ability to manage issues and problems relate to their teaching expertise.

The study of Zeren (2012) focused on the characteristics of students' personalities in term of Piaget's cognitive development theory, Freud's psycho-sexual development theory, Ericson's psycho-social development theory (Zeren, 2012: 2448-2449). Participants should write a personal story about chosen theory connected with his/her life-span.

In our study, not only the self-reflection processes of student teachers were observed, but also their personal construct of expert teacher. Our findings are grounded in personal construct theory. According to its author George Kelly, personal constructs 'refer to thoughts, feelings, intentions etc. that a person is not necessarily aware of. His theory concerns the manner in which personal convictions guide the thinking and actions of people. He advances the idea that, behind the judgment and behavior of a person, an individual theory is hidden.' (Touw, Meijer, Wubbels, 2015:2)

Kelly supposed that people do not behave in correspondence with real characteristics of real world, but on the basis of their personal beliefs about this world. People act as scientists, having their individual categorization system of experiences with the world that leads to their personal constructs about their world. 'It is, then, a theory of man's personal inquiry - a psychology of human quest' (Kelly, 2005: 3).

Although personal constructs have individual nature, people are interested in constructs of others and they can modify their constructs under influence of interactions with others (or after some other important experiences) (Plháková, 2006: 262). Personal construct system is often observed in contrasts, by repertory gird technique. 'According to Kelly, an individual personal construct system consists of double entities or 'contrast poles'. Their meanings can only be established in contrast to the other 'pole', for example, brave-afraid, brave-anxious or brave-quit. These examples of constructs do not illustrate the concept brave, but rather a bipolar formation: brave versus another pole. The contrast gives meaning to the content of both poles of the construct.' (Touw, Meijer, Wubbels, 2015:2). As in some another studies (eg. Nasri et al., 2011), repertory gird technique is not used in our study, because observing of personal constructs is a 'secondary product' of content analysis of self-reflective essays, so student teachers' constructs of expert teacher are taken as a set of their statements about good teachers in their essays.

The theory of personal constructs was implemented in the area of teachers' professional development e.g. by Nasri et al. (2011). The authors result from the fact that there are many studies dealing with students' personal beliefs and their connection to learning approaches and outcomes, but much less studies about teachers' epistemological beliefs and their connection to teaching practices. They created a set of questionnaires to identify personal constructs by novice and expert Science teachers to observe similarities and differences. 'The understanding of these problems is deemed crucial because teachers' beliefs on their function will be reflected on their action that is teaching approaches used and goals of teaching' (Nasri et al., 2011: 2825).
The study focused on two main constructs: personal characteristics and teaching strategies. In the first construct, both groups (novices and experts) assigned as important for Science teacher these characteristics and elements of behavior: being fair, having positive attitude, using humor in class, creative in delivering lesson, willing to admit offence, have high expectation on each student, not to be strict and arrogant. By second construct (teaching strategies), expert teachers stressed importance of creating active teaching and learning, using flexible teaching strategies that suit each student's learning style and relating each lesson content to daily life activity, whereas novice teacher emphasized only importance of having in-depth knowledge in Science and latest Science pedagogical skills. This difference is propably caused by the fact that novice teachers are not comfortable in dealing with unstructured teaching style (Nasri et al., 2011: 2826). Authors concluded that 'identifying science teacher personal construct, Science teacher will be more aware of how their thinking affects behavior and most importantly their teaching mode' (Nasri et al., 2011: 2826).

The study of Touw, Meijer and Wubbels (2015) focused on identification of student teachers' perceptions about their pupils in special schools and on creating of a method to categorize these constructs. The aim of the study is to investigate beliefs that student teachers create about their pupils and that may significantly influence their expectations from these pupils, their relationships and interactions with them (Touw, Meijer, Wubbels, 2015:1). The authors try to understand development of teachers' construct about their pupils. A functional goal of this study is 'to improve the guidance during their teacher education. This is especially useful for articulating constructs that were previously unarticulated. The primary aim of this study is to develop and describe a coding system for these beliefs'(Touw, Meijer, Wubbels, 2015:2).

On the basis of their research findings, the authors created a Classification System for Teachers' Personal Constructs (CSTPC), including following categories: attitudinal, emotional, relational, personal, intellectual, interests and physical (Touw, Meijer, Wubbels, 2015:6). Student teachers from the research sample most used constructs that were categorized as Attitudinal. These constructs refer to the meaningful, valuable and characteristic aspects teachers notice about their pupils when they think and act. The second most frequently occurring category is Relational (constructs about the social functioning of pupils and pupils' relationships with others). The third most frequently mentioned category was Emotional (constructs about a pupils' emotional and psychological functioning). The fourth category was Personal, relating to pupils' actions and the way they perform them. The constructs in this category describe the individuality of a person. It is remarkable that category Intelectuall that could be quite crucial for education (constructs about intellectual functioning and school achievement; about learning performance: the learning progress and performance in academic subjects) was only the fifth frequently mentioned category. (Touw, Meijer, Wubbels, 2015:6-8)

Although this study differs from our research that focuses more on future teachers' personal constructs of expert teacher than on constructs of pupils, findings of Touw, Meijer and Wubbels brings important information about self-reflection of teachers' attitudes and relationships with their pupils or students. 'Since the extent to which someone has positive or negative expectations of another person may have far-reaching implications for 
their relations with that person (Pajares, 1992), understanding teachers' constructs about their pupils is an important topic of research' (Touw, Meijer, Wubbels, 2015:1).

Zeren (2012) worked on the assumption that 'in terms of professional development, teachers' ability to understand themselves and to have awareness about their inner selves may affect their attitudes and behaviors towards their students' (Zeren, 2012: 2445). This assumption is crucial also for our pilot study dealing with ability of students to realize their personal characteristic and abilities helping them to manage their future profession. The goal of the study is to identify which characteristics students used to describe their predispositions to become a teacher, to categorize them according to their positive or negative denotation and to assign these expressions to fundamental psychic processes and structures. Self-reflective statements are observed in connection with participant s' personal construct of expert teacher. These findings will be used as groundwork for future research with more quantitative orientation and as a feedback for the education of Educational Psychology at Department of Economic Teaching Methodology at University of Economics, Prague.

The orientation of our pilot study is idiographic and reflects a hermeneutic-narrative tradition of a research (Miovský, 2006). The significance of quantitative results will be verified by future research.

\section{Materials and Methods}

The content analysis method (Disman, 2011) was applied on essays of students who were asked to write an essay called 'Why am I supposed to be a good teacher' as a part of their assessment in a course of Educational Psychology. They were told to summarize their characteristic that would help them to manage the profession of a teacher. In correspondence with theory of positive psychology (Seligman, 2004), the students should describe positive characteristic. They could mention their negative characteristics as well, but they should suggest some possibilities how to improve themselves in those areas (some kind of intervention, time-management, relaxation etc.).

A sample size was 60 students of a master degree program (45 women and 15 men), 33 students participated in the first phase of research, 27 in the second phase. A desiderative length of the essay was two standard pages and students had approximately three months for writing this essay.

In collected essays, all expressions describing self-reflective characteristics were identified and divided into categories according to their relation to fundamental psychic processes and structures. Each category had two dimensions, reflecting positive or negative denotation of expressions (strengths or weaknesses).

The research was implemented during one academic year with two groups of students (winter and summer semester). The first phase of the research focused entirely on the self-reflective statements and their categorization. It was the first research probe focused on the mapping of the students' self reflective processes (Krejčová, 2015). The aim of the second phase was to validate and enlarge our findings from the first phase. Moreover, an interpretation of a 'good teacher' or expert-teacher was observed. Our intention was to find out which skills and personal traits of a teacher are considered as important for the parcipiants of this research, because this construct could significantly affect their self-reflection in role of a teacher.

\section{Results and Discussion}

During the content analysis of the first group of essays (33 participants), 308 self-reflective statements were identified and divided into 11 categories according to their relation to fundamental psychic processes or structures (see Table 1). Moreover, two dimensions were distinguished: strengths (the expression was used in some positive context) and weaknesses (the expression was used in some negative context). Some expressions (e.g. 'perfectionism') were designated as strength in one essay and as weakness in another. One student described 'responsibility' as her strength and weakness simultaneously, so it was counted twice in both strength and weaknesses.

\begin{tabular}{|l|c|c|}
\hline Category & Strengths & Weaknesses \\
\hline Creativity & 12 & 2 \\
\hline Emotions & 17 & 12 \\
\hline Motivation & 34 & 3 \\
\hline Organization & 10 & 3 \\
\hline Personality & 43 & 23 \\
\hline Presentation & 6 & 7 \\
\hline Self-confidence & 2 & 12 \\
\hline Social skills & 37 & 20 \\
\hline Stress & 7 & 8 \\
\hline Volition & 29 & 15 \\
\hline Others & 3 & 3 \\
\hline Total & 200 & 108 \\
\hline
\end{tabular}

Tab. 1: Categorization of self-reflective statements in first phase

Compared with described models of professional skills of a teacher (Gillernová, 2008, Kyriacou, 1998), students described much more social skills than theoretic or didactic skills. This fact can be interpreted in connection with the content of course of Educational Psychology that is orientated more on social and diagnostic skills than on theoretic and didactic skills trained in other courses.

Students referred more about their strengths than about their weaknesses. The only areas where weaknesses predominated were Self-confidence, Stress and Presentation. Some expressions were used in more essays. The most frequent expressions from strengths were 'empathy' (described by 14 students, i.e. almost half of participants) and 'active listening' (described by 11 students). This fact might be also related to the course of Educational Psychology in which both these skills were trained. The most frequent expression from weaknesses was 'conflict avoidance' (described by 8 students).

To clarify the process of content analysis, more frequent expressions from some categories is described. All three expressions mentioned above (empathy, active listening and conflict avoidance) were assigned to category of Social skills. In Emotions, more students mentioned 'extrovert' and 'well-balanced' as strengths and 'nervous' and 'impulsive' as weaknesses. In Motivation, most frequent strengths were 'I enjoy transferring knowledge', 'I can motivate other people'. In Characteristics of Personality, more students described themselves as 'friendly' and 'rightful' in strengths and as 'perfectionistic' and 'stubborn' in weaknesses. In Volition, the most frequent strengths were 'precise' and 'patient', the 
most frequent weaknesses were "impatience" and "tendency to procrastination'.

In the next research phase with second group of respondents (27 students), 284 self-reflective statements were identified (see Table 2). Almost the same categorization as in the first phase was used with one exception, one category summarizing statements about development of students' thinking processes and strategies was added (such as 'understanding to student' $\mathrm{s}$ way of thinking', 'to analyse information in a logical structure and to transmit it clearly and easily'). In a dimension of strengths and weaknesses, participants in a second phase used 243 positive and 41 negative expressions.

\begin{tabular}{|l|c|c|}
\hline Category & Strengths & Weaknesses \\
\hline Creativity & 7 & 1 \\
\hline Emotions & 21 & 2 \\
\hline Motivation & 31 & 1 \\
\hline Organization & 3 & 1 \\
\hline Personality & 59 & 4 \\
\hline Presentation & 13 & 5 \\
\hline Self-confidence & 1 & 2 \\
\hline Social skills & 48 & 5 \\
\hline Stress & 2 & 7 \\
\hline Volition & 40 & 9 \\
\hline Thinkig & 7 & 0 \\
\hline Others & 11 & 4 \\
\hline Total & 243 & 41 \\
\hline
\end{tabular}

Tab. 2: Categorization of self-reflective statements in second phase

As in the first phase, students referred more about their strengths than about their weaknesses. Weaknesses predominated only in Self-confidence and Stress. The most frequent expression from strengths was 'empathy' again, described by 11 students. Next frequent expressions were 'patience' (10 students) and 'rightfulness' (8 students). Responses in weaknesses were quite variable, only 'impatience', 'unpunctuality' and 'anxiety from bigger audience' were marked twice.

\begin{tabular}{|l|c|c|}
\hline Category & Strengths & Weaknesses \\
\hline Creativity & 19 & 3 \\
\hline Emotions & 38 & 14 \\
\hline Motivation & 65 & 4 \\
\hline Organization & 13 & 4 \\
\hline Personality & 102 & 27 \\
\hline Presentation & 19 & 12 \\
\hline Self-confidence & 3 & 14 \\
\hline Social skills & 85 & 25 \\
\hline Stress & 9 & 15 \\
\hline Volition & 69 & 24 \\
\hline Thinking & 7 & 0 \\
\hline Others & 14 & 7 \\
\hline Total & 443 & 149 \\
\hline
\end{tabular}

Tab. 3: Categorization of self-reflective statements in both phases

In Table 3, findings from both research phases are summarized. Some findings from this summarization are quite obvious, because data from both phases have this tendency: students reffered much more frequently about their strengths (443 statements) than about their weaknesses (149 statements); the only areas where weaknesses predominated are Self-confidence and Stress. These findings deserve further exploration, but might be partially explained by the fact that students handed their essays before the last lesson that focused on stress and its prevention. Lower self-confidence might be caused by the lack of experiences in the teacher's role.

Remarkable are the largest categories: in the first phase, the largest categories in strengths were Personality, Social skills and Motivation and in weaknesses Personality, Social skills and Will. In the second phase, the largest categories in strengths were Personality, Social skills and Will and in weaknesses Will, Stress, Presentation and Social skills. When all the statements in table 3 were summarized, the largest categories in both strengths and weaknesses are Personality, Social skills and Will. It means that in bigger sample of respondents, these three categories are the most frequent (and thereby propably most important) in selfreflections of student teachers from our research sample. Next remarkable finding is that in both research phases was identical most frequent expression: 'empathy'. This social skill seems to be crucial for the self-reflection of future teachers in our sample, which is probably influenced by the content of course of Educational psychology.

To investigate a construct of 'expert teacher' in participants' essays, the content analysis method was used as well. Although the definition of 'good teacher' was not obligatory nor suggested part of essay, majority of students (18 from 27) mentioned some definition or partial characteristics of a good teacher. In analysis of these texts, 65 statements were found. The most frequent expressions were 'rightful' and 'interested in his/her subject, enthusiatistic' (5 respondents by each statement). Next frequent expressions were 'respect, authority' (4 respondents); 'good relationship with students', 'communication skills' 'honest' and 'creative' (3 respondents by each statement); 'understanding', 'self-improvement', 'motivating', 'is able to admit a mistake', 'understands his/her subject and can explain', 'decisive' and 'friendly' (2 respondents by each statement). Other expressions were mentioned only once (respectively by one participant), but they are also part of personal construct of good teacher in our study: 'holder of moral values, presentation skills, not rush and impetuous, punctual, honest, can teach a lot, purposeful, organization and didactic skills, partner, entertaining, amusing, unconflicting, calm, able to commend and to restrict personal needs' (restricting of personal needs as a characteristic of good teacher is very disputable because of psychohygienical reasons, but it is serious part of students' statements).

The most frequent expression from this part of research ('rightful') is also one of the most frequent expressions from the self-reflections in second phase. Like in self-reflective statements, participants mentioned mainly personal traits and social skills in their definitions of good teacher. These findings supports the assumption that future teachers' construct of a good teacher affects their self-reflection as a teacher.

To verify and enrich our findings, a follow-up quantitative research using some methods of text mining would be appropriate (e.g. Manning, Schütze, 1999). Despite small sample size, results are highly relevant for the course of Educational Psychology and other education and training in the Department of Economic Teaching Methodology at University of Economics, Prague. Because majority of students wrote the essays at the end of the semester, some effect of the content 
of the course can be presumed. The most frequented positive expressions in the first phase were 'active listening' and 'empathy'. Both these abilities were repeatedly mentioned and trained in the course. Conversely, less space was given to ability of successful solutions of conflict and 'conflict avoidance' was the most frequent expression from weaknesses in the first phase. Some training of effective solution of conflicts and assertiveness in course of Educational Psychology would be probably helpful also for students' self-confidence that was the one of categories in that negative expressions markedly predominated.

Although students seemed surprised by the fact that they should reflect themselves in the essay and worried if they were able to manage this type of assignment, finally they found the selfreflection very useful and enriching:

- 'This essay was a great opportunity to try to reflect myself, to sum up my abilities, weaknesses and predispositions to be a teacher. It also helped me to realize my motivation to work as a teacher.'

- 'At first, I took this essay only as an obligation that helped me to gain points. However, I realized the acquisition for my personality. I was thinking about myself, what kind of person I am and what I can improve.'

- 'At first, I asked: How can I know if I am supposed to be a teacher? I have no experience with teaching. Simultaneously, I was pleasantly surprised by this task and by the fact that we (students at university) are finally forced to think, not only to memorize and to rewrite textbooks.'

- 'It would be useful to write such self-reflection after ten years and to repeat it in ten-years periods.'

- 'I learned from this essay a lot, e.g. that it is important to appreciate not only the others, but myself as well. I considered deeply about my motivation to be a highschool teacher. (...) I found out that I need to use my strengths in all challenges in my life so I can overcome the obstacles better. It would be useful for each man to try this self-reflection.'

Our findings were compared with the article of Arif et al. (2012). They measured the Big five personality traits of future teachers at teacher education institutes of Punjab, Pakistan. They found that 'the ratio of four personality traits (Extraversion, Agreeableness, Conscientiousness, and Neuroticism) was nearly the same, but the ratio of Openness personality trait is greater which means that the openness personality trait of prospective teachers is more dominant as compared to remaining four big personality traits' (Arif, et al., 2012: 161).

Despite the research has different methodology and terminology from our study, some findings can be concluded. In the study of Arif et al. (2012), Openess (characterized as 'curious, intellectual, creative, cultured, artistic, sensitive, flexible imaginative'(Arif et al., 2012: 163) overwhelmed. In our study, much less expressions were identified in category Creativity (that could be close to Openess) than in Social skills. The category of Social skills (empathy, active listening etc.) could be related to Agreebleness from the Big Five, characterized as 'Co-operative, worm caring, good-natured, Courteous trusting' (Arif et al., 2012: 163).Moreover, the ratio of Agreebleness was not higher than ratio of Extraversion, Conscientiousness, and Neuroticism and was lower than ratio of Openess.
This difference from our study could be explained by a fact that in research of Arif et al. (2012), Agreebleness was significantly higher in women that in men. Both studies have different genderproportion: 45 women to 15 men in our research and 60 women to 40 men in the study of Arif et al.(2012). Consequently, difference in our results could be caused by different gender proportion. Therefore, it would be interesting to study gender differences in self-reflective essays in our future research.

As Majzub (2013), our study concluded that the self-reflective reports during teaching practicum had positive impact on awareness of students' learning and teaching skills. Some future research during training teaching of the participants of our research could study impact of self-reflection skills on the ability to manage issues and problems related to their teaching expertise.

In research of Zeren (2012) students should write some personal stories within a framework of classical theories in developmental psychology. Participants stated that this task positively influenced their self-awareness and understanding towards children and youngsters (Zeren, 2012: 2445). Our study was concentrated more on explicit naming and describing of strengths and weaknesses in relation to profession of a teacher. Because of a strong connection between speech and mind (Vygotskij, 1986), this type of task should help students to think more efficiently about themselves in the role of a teacher.

The study of Nasri et al. (2011) focused on constructs of personal characteristics and teaching strategies by novices and expert teachers. Novices teachers seemed to be uncomfortable with unstructured teaching style, neglecting didactic skills like creating active teaching and learning, using flexible teaching strategies and relating each lesson content to daily life activity. Unlike in our study, teacher novices relied more on in-depth knowledge in Science and latest Science pedagogical skills (Nasri et al., 2011: 2826). In contrast, future teachers in our study perceived importance of creativity, flexibility and transcendence in teaching strategies describing good teacher like 'interested in his/her subject, enthusiatistic' (5 respondents); 'creative' (3 respondents); 'self-improvement','motivating' 'understands his/her subject and can explain', (2 respondents). These findings can be supported with fragments of analysis of self-reflective essays:

- 'It is important for a teacher to think creatively and to use entertaining methods of teaching.'

- 'Preparing for my teaching I tried to be creative and originative, because I consider creativity as one of basis characteristics of a good teacher.'

- $\quad$ 'I would like to conclude my essay by motto of Ch. F. Browne: 'The average teacher tells. The good teacher explains. The great teacher demonstrates. The best teacher inspires.'

\section{Conclusion}

Our study proved that a self-reflective essay can significantly enrich the preparation of future teachers, helping them to realize their strengths and weaknesses and to develop their professional expertise. The students appreciated this type of task as an opportunity to think about themselves and their pedagogical skillss, personal characteristic and dispositions related to profession of a teacher. Despite small sample size, results of content analysis are highly relevant as a source of information 
about the self-awareness of students and as a feedback for the course of Educational Psychology that could positively influence its effectiveness.

This pilot study will be followed by a quantitative research with larger samples, using methods of data mining and factor analysis to bring significant and detailed findings about personality of students. The study will compare differences in responses of men and women and differences between the essays from Educational Psychology and self-reflections that students write later (during their training teaching at secondary schools) to analyze development of students' responses after confrontation with real practice.

Other following study should investigate personal constructs of expert teacher more deeply than in present study, using the repertory gird technique to improve reliability of our findings. An analysis of student teachers' personal constructs of pupils (or students) with help of Classification System for Teachers' Personal Constructs (CSTPC) by Touw, Meijer, Wubbels (2015) could be enriching for development of positive attitudes and relationships between teachers and their students not only during their training education, but in their future profession as well.

Such studies could importantly enrich the education and personal training of students in Department of Economic Teaching Methodology at University of Economics, Prague and could be exploitable for other institutions dealing with teachers' education and personal growth.

\section{Acknowledgements}

Research was supported by Internal Grant Agency of University of Economics, Prague (IGA) - project F1/31/2015 and it is part of a project of Faculty of Finance and Accounting realized with help of institutional support VŠE IP100040.

\section{References}

Arif, M. I., Rashid, A., Tahira, S. S., and Akhter, M. (2012) 'Personality and Teaching: An Investigation into Prospective Teachers' Personality', International Journal of Humanities and Social Science, vol. 2, no. 17, pp. 161-171.

Bandura, A. (1977) 'Self-efficacy: Toward a Unifying Theory of Behavioral Change', Psychological Review, vol. 84, no. 2, pp. 191-215.

Disman, M. (2011) How to produce sociological knowledge, Prague: Karolinum.

Freddano, M., Siri, A. (2012) 'Teacher Training For School SelfEvaluation', Procedia - Social and Behavioral Sciences, vol. 69, pp. 1142-1149. http://dx.doi.org/10.1016/j.sbspro.2012.12.044 Gillernová, I. (2008) 'Social skills of teachers and possibilities of their development in school enviroment', in Mertin, V. et al. (ed.) Pedagogical and Psychological Assessment, Prague: Raabe.

Hayes, N. (1993) Principles of Social Psychology, Abingdon: Psychology Press.

Körpülü, Ö. (2012) 'Using Classroom assessment Techniques (CAT) and Diary Keeping in Teacher Training', Journal of Efficiency and Responsibility in Education and Science, vol. 5, no. 1, pp. 1-9. http://dx.doi.org/10.7160/eriesj.2012.050101

Kelly, G. A. (2003) 'A Brief Introduction to Personal Construct Theory', in F. Fransella (ed.) International Handbook of Personal Construct Psychology, Chichester: John Wiley \& Sons, Ltd.

Krejčová, K. (2015) 'Self-reflection of Students of Economic
Teaching', Proceedings of the 12th International Conference Efficiency and Responsibility in Education 2015, Prague, pp. 297-302.

Kyriacou, Ch. (1998) Essential Teaching Skills, Cheltenham: Nelson Thornes.

Majzub, R. M. (2013) 'Teacher Trainees' Self Evaluation during Teaching Practicum', Procedia - Social and Behavioral Sciences, vol. 102, pp. 19 -203. http://dx.doi.org/10.1016/j. sbspro.2013.10.733

Manning, Ch. D., Schütze, H. (1999) Foundations of Statistical Natural Language Processing, Cambridge: MIT Press.

Miovský, M. (2006) Qualitative Research and Methods in Psychological Research, Prague: Grada.

Mogonea, F., Mogonea, F. R. (2013) 'Practical and applied aspects regarding the development of the self-evaluation ability of students-future teachers', Procedia - Social and Behavioral Sciences, vol. 76, pp. 53 -535. http://dx.doi.org/10.1016/j. sbspro.2013.04.159

Nasri, N. M., Yusofb, Z. M., Ramasamyc, S., Halimd, L., Minge, L. W.(2011) 'Personal constructs: novice and expert science teachers concerning teacher function', Procedia Social and Behavioral Sciences, vol. 15, pp. 2823-2826. http://dx.doi. org/10.1016/j.sbspro.2011.04.196

Plháková, A. (2006) History of Psychology, Prague: Grada.

Seligman, M. (2002) Authentic Happiness, New York: Simon and Schuster.

Sternberg, R. J., Horvath, J. A. (1995) 'A Prototype View of Expert Teaching', Educational Researcher, vol. 24, no. 6, pp. 9-17.

Švarcová, E. (2010) 'Ethical Education at Schools', Journal of Efficiency and Responsibility in Education and Science, vol. 3, no. 1, pp. 36-41.

Touw, H. M. F., Meijer, P. C., Wubbels, T. (2015) 'Using Kelly’s Theory to Explore Student Teachers' Constructs about their Pupils', Personal Construct Theory \& Practice, vol. 12, pp. $1-14$.

Vygotskij, L. S. (1986). Thought and Language. Cambridge: MIT Press.

Zeren, S. G. (2012) 'Can Piaget, Freud or Erikson explain my self-development? Preservice teachers' personal evaluation', Procedia - Social and Behavioral Sciences, vol. 46, pp. 24452450. http://dx.doi.org/10.1016/j.sbspro.2012.05.500 